\title{
Exploring links between the sustainability performance of urban public transport and land use in international cities
}

\author{
Graham Currie \\ Monash University \\ graham.currie@monash.edu
}

\author{
Chris De Gruyter \\ Monash University \\ chris.degruyter@monash.edu
}

Abstract: Sustainability is a major driver of world policy for cities, and public transport is said to be a more sustainable mode of travel than other modes. But how do public transport (PT) systems in different cities compare to each other? This paper measures the relative sustainability of public transport systems between cities rather than between modes within cities. However, its primary focus is to explore the extent to which public transport sustainability is influenced by land use. Do cities with low-density land use automatically have poor sustainability performance? Do highdensity megacities always have good sustainability performance relative to other cities? Does land use mean some cities cannot improve sustainability performance? These are some of the questions this research seeks to explore through an empirical study of land use and PT sustainability metrics using correlation/cross sectional and regression analyses.

Results suggest that westernized, developed countries (Western Europe, North America, and Oceania) have good environmental and social sustainability performance but poor service effectiveness and economic performance. Asia and Latin America perform the other way around, better on economic and service effectiveness and worse on social and economic performance. Eastern Europe is the one region with higher sustainability performance all around. Prague, Dakar and Tokyo are at the top of 98 cities studied, while Dubai, Shizuoka (Japan), Denver, and Johannesburg perform the worst.

Land-use results show that population and job density present the highest correlation with PT sustainability metrics, implying that about a third of overall sustainability performance of public transport in cities might be explained by land use. Higher-density land use improves sustainability performance. A wider range of land-use indicators is more strongly correlated with the service effectiveness categories of sustainability indicators and to less strongly correlated with the economic sustainability indicators, suggesting that Western cities with poor service effectiveness and economic sustainability performance should densify cities to address sustainability challenges.

Policy implications and areas for future research are explored.

Keywords: Public transport, transit, sustainability, land use, cities, world review

\section{Article history:}

Received: October 19, 2016

Received in revised form:

September 1, 2017

Accepted: December 7, 2017

Available online: March 14,

2018

Copyright 2018 Graham Currie \& Chris De Gruyter

http://dx.doi.org/10.5198/jtlu.2018.957

ISSN: 1938-7849 | Licensed under the Creative Commons Attribution - Noncommercial License 4.0

The Journal of Transport and Land Use is the official journal of the World Society for Transport and Land Use (WSTLUR) and is published and sponsored by the University of Minnesota Center for Transportation Studies. This paper is also published with additional sponsorship from WSTLUR. 


\section{Introduction}

It is a commonly held belief of the transport research community that urban public transport systems are, by their very nature, more "sustainable" than private car based transport systems due to their relative social, economic and environmental performance (Vuchic, 1999; Litman, 2009). In 2015 the United Nations set a target that by 2030 access to "safe, accessible and sustainable transport" would be available to all (United Nations, 2015). This target sets a sustainability challenge for cities since improving public transport systems to realize these aims is not an easy task.

In response to this challenge the authors have sought to identify ways to answer some new and related questions; just how sustainable are public transport systems in cities? And how can sustainability performance be measured and thus improved? Our approach was to develop a series of sustainability metrics which used the recently published UITP databases on city transit system performance to measure economic, social, environmental and effectiveness sustainability measures for a series of world regions. ${ }^{1}$ This research was published in 2016 (De Gruyter, Currie, \& Rose, 2017) and illustrated that in general public transport in Eastern European cities had good all round sustainability performance for environmental, social, economic and system effectiveness measures. Western developed countries (Western Europe, North America and Oceania) have good environmental and social indicator performance but poor system effectiveness and economic performance. Asia and South American cities have performance the other way around (good system effectiveness and economic performance but poor otherwise).

This research paper explores related concerns regarding land use and how it relates to the sustainability performance of urban public transport in cities. Sustainability performance outcomes are influenced by how a city's public transport system is designed, funded and operated but to what extent is this performance also influenced by the urban form of that city? Much research already shows clear links between land use and transit ridership performance (Kenworthy \& Laube, 1999). However, none of this research has linked this to the sustainability performance of public transport. So is poor sustainability performance of a transit system a foregone conclusion in a city with low density dispersed development? Conversely are high density "super cities" always going to be high sustainability performers? If land-use influences on the sustainability performance of urban public transport can be isolated, it may thus be possible to better understand the contribution of design, policy, funding, operations and management.

This paper explores the influence of land-use related measures to the overall sustainability performance metrics of public transport in cities using a methodology developed by the authors (De Gruyter et al., 2017). The general approach is to empirically explore the links between land-use related measures and outcome aggregate sustainability scores using a correlation based and cross sectional sustainability area analysis for cities.

The paper is structured as follows; the next section outlines the research context to this field including published work on sustainability of public transport and the methodology employed to measure the sustainability performance of cities from the authors previous research (De Gruyter et al., 2017). The research method is then presented followed by the results. The paper concludes with a summary of key findings including suggestions for policy implications and areas for future research.

\section{Research context}

Sustainability has traditionally been defined as "...development that meets the needs of the present without compromising the ability of future generations to meet their own needs." (Brundtland Commission, 1987). More recently, this definition has been refined to acknowledge the role of the earth's

\footnotetext{
${ }^{1}$ The analysis also reported results for cities in Asia and the Middle East but no city based results for the rest of the world have been reported to date. This is reported in this paper for the first time.
} 
life-support system, as follows: "Development that meets that needs of the present while safeguarding Earth's life-support system, on which the welfare of current and future generations depends." (Griggs et al., 2013). This underlying support system is increasingly recognized as having economic, social and environmental dimensions, reflecting the three pillars of sustainable development (Brundtland Commission, 1987).

The sustainability of transport systems has been measured by previous research in the context of sustainable development, with various indicators and frameworks used to capture economic, social and environmental dimensions (Dobranskyte-Niskota, Perujo, \& Pregl, 2007; Litman, 2009; Castillo \& Pitfield, 2010; Jeon, Amekudzi, \& Guensler, 2010; Haghshenas \& Vaziri, 2012). Haghshenas and Vaziri (2012) assessed the sustainability performance of transport systems in 90 international cities using a composite index containing nine indicators:

- Economic: transport expenditure, average user cost, average time spent in traffic

- Social: transport related fatalities, transport accessibility, variety of transport options

- Environmental: transport emissions, energy use, land consumption for transport

Their analysis found that cities in developed parts of Asia and Europe (such as Hong Kong, Shanghai, Bern and Stuttgart) performed relatively well in comparison to other cities due to their greater emphasis on public transport, walking and cycling.

More recently, a number of studies have focused specifically on the sustainability performance of public transport systems. This work was pioneered by Miller (2014) who developed a framework to assess the sustainability performance of 33 heavy and light rail systems throughout the United States. The framework developed by Miller (2014) included a total of 20 indicators, grouped into economic, social, environmental and system effectiveness categories. Miller, de Barros, Kattan, and Wirasinghe (2016) then expanded this work by testing a range of data normalization and weighting techniques in assessing the sustainability performance of different public transport modes for the Broadway Corridor in Vancouver, Canada.

Previous research by the authors (De Gruyter et al., 2017) has drawn upon and adapted Miller's framework to assess and compare the sustainability performance of urban public transport systems in different world regions, with a particular focus on selected cities in Asia and the Middle East. The adapted framework, as shown in Table 1, contains a total of 15 indicators, grouped into the same four headings used by Miller (2014) to reflect key dimensions of public transport sustainability. The main motivation for choice of indicators was the need to cover off elements of the Miller framework (the 4 dimensions of sustainability. The available data sources were then scanned to identify indicators that might measure aspects of these dimensions. The final indicator set are the best available from published sources. Indicators for each city were sourced primarily from the International Association for Public Transport (UITP, 2001; UITP, 2015) and were normalized to allow comparisons to be made between regions and cities. Indicators were assigned equal weight in the assessment process given the absence of any sufficient evidence to suggest particular aspects of public transport sustainability are universally more important than others (Haghshenas \& Vaziri, 2012; Miller et al., 2016). Results of the assessment showed that Eastern Europe performed best, achieving high scores on all key dimensions, particularly social sustainability. This was followed by Asia and Latin America which both performed well in terms of their economic sustainability and service effectiveness scores. 
Table 1: Indicators for assessing urban public transport sustainability

\begin{tabular}{|c|c|c|c|}
\hline ID & Indicator & Units & Desirability \\
\hline A & ENVIRONMENTAL & & \\
\hline A1 & Quantity of energy consumed & $\mathrm{MJ} / \mathrm{pkm}^{2}$ & Less is desirable \\
\hline A3 & Mass of total pollutants emitted (e.g., NOx, VOC, CO2) & $\mathrm{kg} / \mathrm{ha}$ & Less is desirable \\
\hline A5 & Land area consumed by public transport facilities & $\%$ of urban area & Less is desirable \\
\hline B & SOCIAL & & \\
\hline B1 & Travel Participation ${ }^{3}$ & $\mathrm{pkm} /$ capita & More is desirable \\
\hline B4 & Average user trip distance & $\mathrm{km}$ & Less is desirable \\
\hline B5 & Affordability & $10-^{4} \%$ per capita GDP/trip ${ }^{4}$ & Less is desirable \\
\hline B9 & Public transport related deaths & fatalities/billion-pkm & Less is desirable \\
\hline $\mathrm{C}$ & ECONOMIC & & \\
\hline $\mathrm{C} 1$ & Annual operating cost & $\$ \mathrm{US}_{\mathrm{pkm}}^{4}$ & Less is desirable \\
\hline $\mathrm{C} 4$ & Cost recovery (proportion of costs recovered) & $\%$ of total costs & More is desirable \\
\hline C6 & Passenger km travelled per unit GDP & $\mathrm{pkm} / \$ \mathrm{US}^{4}$ & More is desirable \\
\hline C8 & Average time per trip & mins & Less is desirable \\
\hline $\mathbf{D}$ & SYSTEM EFFECTIVENESS & & \\
\hline D1 & Average occupancy rate of passenger vehicles & $\%$ of seated capacity & More is desirable \\
\hline D3 & Annual public transport trips per capita & trips/capita & More is desirable \\
\hline D4 & Public transport mode split & $\%$ of all trips & More is desirable \\
\hline D5 & Public transport fleet size & vehicles/million people & More is desirable \\
\hline
\end{tabular}

Source: De Gruyter et al. (2017)

While the work by De Gruyter et al. (2017) has assessed the sustainability performance of urban public transport systems in different regions of the world, no research has examined its association with land use. The research underlying this paper therefore seeks to explore the link between public transport sustainability and land use in cities. Land use has been shown to have a strong influence on travel behavior, particularly automobile dependence (Kenworthy \& Laube, 1999; Cervero, 2013; Litman, 2016). Kenworthy and Laube (1999) found that higher urban densities are strongly associated with lower levels of car ownership and car use. Related evidence suggests that higher urban densities are also associated with lower transport energy consumption and higher levels of public transport use in cities (Newman \& Kenworthy, 2006). Taking a broader view, Ewing and Cervero (2010) discuss the influence of land use on travel behavior in terms of the 5 Ds: density, diversity, design, distance to public transport, and destination accessibility. In addition, Geerlings and Stead (2003) note the importance of integrating land use and transport planning for achieving sustainable cities.

\section{Research method}

This section outlines the research method used to explore the link between public transport sustainability and land use in cities. Key data sources and cities are described first, followed by an overview of selected indicators and the data analysis process that was used.

\footnotetext{
${ }^{2} \mathrm{Pkm}=$ passenger kilometers

${ }^{3}$ This metric is termed "system accessibility" in our original research but we have agreed with a reviewer who suggested this be changed

${ }^{4}$ The use of separate GDP based and \$US based metrics may seem questionable to some readers. GDP based metrics assess affordability as a relative share of economic output. \$US based metrics concern value or costs in equivalent international terms of value; these are very different measures hence there is no apparent conflict between the use of separate GDP based and \$US based metrics in the research.
} 


\subsection{Key data sources and cities}

Consistent with the previous study undertaken by the authors (De Gruyter et al., 2017), this research used the databases produced by the International Association for Public Transport ${ }^{5}$ (UITP, 2001; UITP, 2015) for sourcing public transport related indicators. The indicators used are those listed in Table 1; all are adopted for this research. In addition to the databases produced by UITP, figures on Gross Domestic Product (GDP) for each city were sourced from The Brookings Institution (2016) while land-use data was compiled from a variety of sources (UITP, 2001; UITP, 2015; Demographia, 2016; OECD, 2016). A total of 98 cities, as shown in Table 2, were included in the analysis and grouped into the regions of Western Europe (32 cities), Eastern Europe (4 cities), North America (15 cities), Latin America (8 cities), Middle East (7 cities), Africa (8 cities), Asia (19 cities) and Oceania (5 cities).

The central rationale for choice of indicators is availability rather than rationality for purpose. Only a limited choice set is available from these sources and this set represents the only choice available in almost all cases. This is far from perfect but in general the indicators chosen fit the general rationale behind the sustainability areas required and many have been defined by the source research behind the development of the metrics (the foundation work for most elements of the indices was Miller, 2014).

Table 2: Cities included in the assessment of urban public transport sustainability

\begin{tabular}{|c|c|}
\hline World region & Cities \\
\hline Western Europe & $\begin{array}{l}\text { Amsterdam, Athens, Barcelona, Berlin, Berne, Bologna, Brussels, Copenhagen, Dusseldorf, Frankfurt, } \\
\text { Geneva, Glasgow, Graz, Hamburg, Helsinki, London, Lyon, Madrid, Manchester, Marseille, Milan, } \\
\text { Munich, Nantes, Newcastle, Oslo, Paris, Rome, Ruhr, Stockholm, Stuttgart, Vienna, Zurich }\end{array}$ \\
\hline Eastern Europe & Budapest, Cracow, Moscow, Prague \\
\hline North America & $\begin{array}{l}\text { Atlanta, Calgary, Chicago, Denver, Houston, Los Angeles, Montreal, New York, Ottawa, Phoenix, } \\
\text { San Diego, San Francisco, Toronto, Vancouver, Washington }\end{array}$ \\
\hline Latin America & Bogota, Brasilia, Curitiba, Mexico City, Rio de Janeiro, Salvador, Santiago, Sao Paulo \\
\hline Middle East & Abu Dhabi, Dubai, Jerusalem, Mashhad, Riyadh, Tehran, Tel Aviv \\
\hline Africa & Abidjan, Cairo, Cape Town, Casablanca, Dakar, Harare, Johannesburg, Tunis \\
\hline Asia & $\begin{array}{l}\text { Bangkok, Beijing, Chennai, Delhi, Guangzhou, Ho Chi Minh City, Hong Kong, Jakarta, Kuala } \\
\text { Lumpur, Manila, Mumbai, Osaka, Sapporo, Seoul, Shanghai, Shizuoka, Singapore, Taipei, Tokyo }\end{array}$ \\
\hline Oceania & Brisbane, Melbourne, Perth, Sydney, Wellington \\
\hline
\end{tabular}

\subsection{Selection of indicators}

The 15 public transport indicators listed in Table 1 were selected for the assessment of public transport sustainability in cities and regions. A total of six land-use indicators were also included in the analysis, as shown in Table 3. The land-use indicators were chosen based on their availability and general acceptance as common indicators of urban form (Schwarz, 2010). While not strictly considered to be a land-use indicator, walking mode split was included in the dataset as a pseudo indicator for walkability; the premise being that cities with a higher walking mode split are likely to be more walkable with this having a strong association with land use. Demographia (2016) was used as a key data source for land-use indicators given it adopts a consistent definition of "built-up" areas in different regions of the world. Other published urban agglomeration lists tend not to use consistently defined entities, mixing metropolitan areas with municipalities (parts of metropolitan areas) and urban areas (Demographia 2016). Except for the sprawl index, all land-use indicators covered almost all the 98 cities used in the analysis. The sprawl

${ }^{5}$ UITP is the French acronym for the International Association of Public Transport 
index, a reflection of the extent of urban sprawl in each city, was only available for 41 out of the 98 cities as this indicator was generally only available for cities located in OECD countries (OECD, 2016).

Table 3: Land-use indicators included in the assessment

\begin{tabular}{llll}
\hline Land-use indicator & Units & Source & Availability \\
\hline Urban population & persons & Demographia (2016) & 97 out of 98 cities \\
\hline Urban population density & persons/ha & Demographia (2016) & 97 out of 98 cities \\
\hline Urban job density & jobs/ha & UITP (2001), UITP (2015) & 97 out of 98 cities \\
\hline Size of urban area & ha & Demographia (2016) & 97 out of 98 cities \\
\hline Sprawl index* & - & OECD (2016) & 41 out of 98 cities \\
\hline Walking mode split & $\%$ & UITP (2001), UITP (2015) & 96 out of 98 cities \\
\hline
\end{tabular}

* The sprawl index measures growth in the built-up area adjusted for growth in the city population. It is equal to zero when both growth in the built-up area and population are stable over time. It is negative when growth in population exceeds growth in the built-up area and is positive when growth in the built-up area exceeds growth in population.

\subsection{Data analysis}

Following the compilation of indicator values for the selected cities, average indicator values specific to public transport sustainability (Table 1) were calculated for each world region (Western Europe, Eastern Europe, North America, Latin America, Middle East, Africa, Asia and Oceania). To enable composite indicators to be developed for each dimension of public transport sustainability (economic, social, environmental and system effectiveness), indicator values were normalized first using a distance to reference based approach, consistent with previous research (Jeon et al., 2010; Miller et al., 2016). The distance to reference based approach results in indicator values having a score between 0 (lowest performance) and 1 (highest performance). Where a lower value for an indicator is seen as more desirable (e.g., operating costs), the following equation was used to normalize the indicator value:

$$
n_{\text {i negative }}=\frac{\min (\text { all } x)}{x_{i}}
$$

Where:

$n_{i}$ negative $=$ normalised value for negative indicator $i$

$x_{i}=$ raw value of indicator $i$

Where a higher value for an indicator is seen as more desirable (e.g., annual public transport trips per capita), the following equation was used:

$$
n_{\text {ipositive }}=\frac{x_{i}}{\min (\text { all } x)}
$$

Where:

$n_{i \text { positive }}=$ normalized value for positive indicator $i$

$x_{i}=$ raw value of indicator $i$

Consistent with previous studies, all indicators were assigned equal weight in the assessment process (Haghshenas \& Vaziri, 2012; De Gruyter et al., 2017). Normalized indicator values could then be averaged within a given category (e.g., economic) to give an overall normalized composite indicator value for that dimension of sustainability. However, in cases of missing data where only one indicator 
value was available for a given category (representing about $5 \%$ of cases), the normalized composite indicator value was not reported since this would not be representative of performance across the entire category. An overall normalized measure of total public transport sustainability was also calculated by averaging normalized values across all indicators.

Following the calculation of normalized composite indicator values for each dimension of public transport sustainability (economic, social, environmental and system effectiveness) and total public transport sustainability for each city, a correlation analysis was undertaken with each land-use indicator. The correlation coefficient $(r)$ was calculated for each combination of public transport sustainability and land-use indicator across all cities. T-tests were used to understand whether each correlation was statistically significant. Regression modelling was also undertaken to understand the impact of different land-use indicators on public transport sustainability. Multicollinearity was tested using the Variance Inflation Factor (VIF) for land-use variables, in which a VIF value in excess of 5 indicates an issue of multicollinearity.

When the above steps were complete, the results were reported using a series of tables and charts. This helped to illustrate associations between public transport sustainability and land use across cities and world regions.

\section{$4 \quad$ Results}

Results are presented in four key parts. First, the city/region based results of sustainability indicator results are presented. Then a disaggregate analysis by component indicator (economic, social, environmental and effectiveness). A correlation based analysis for the land-use indicators and aggregate sustainability scores is then presented. Finally mapping of indicators against aggregate scores is undertaken.

\subsection{Aggregate city/region score results}

Figure 1 presents the results of the aggregate normalized sustainability score values for international cities and regions. For the international regions, Figure 1 suggests that: Eastern Europe, Asia and Latin America achieve the highest aggregate normalized scores in that order. Eastern Europe has the highest rating results of all regions which is a result of high scores on all scales but particularly a first-place rating for social indicators, a second place for environmental and third place for the others. Asia is second ranked because it has a first-place rating for both service effectiveness and economic indicators. It is however rated only 5 th and 6 th out of the 8 regions for social and environmental indicators respectively. 


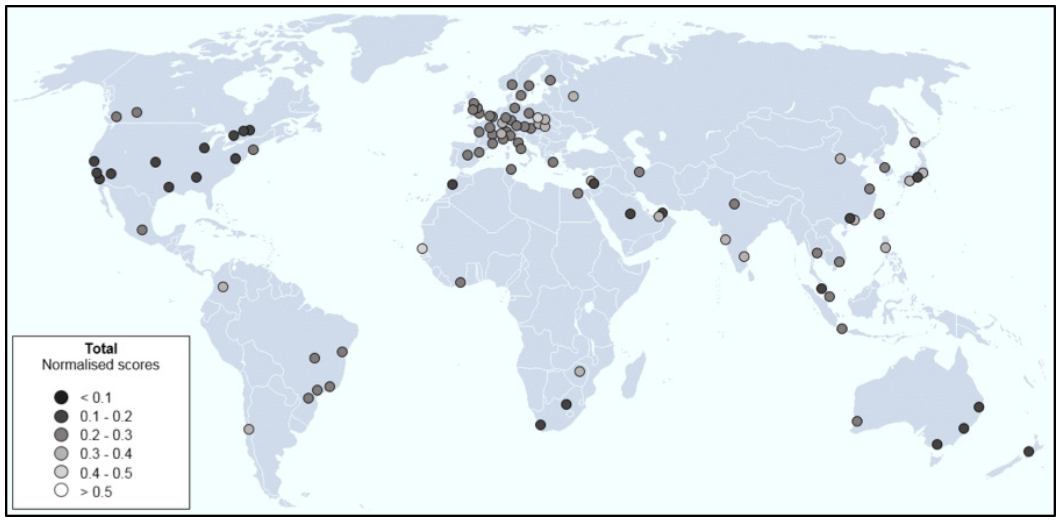

\begin{tabular}{|c|c|c|c|c|c|c|c|c|c|c|}
\hline Country & City & Total & Rank & Country & City & Total & Rank & REGION & Total & Rank \\
\hline \multicolumn{4}{|c|}{ Western Europe } & \multicolumn{4}{|c|}{ Latin America } & & & \\
\hline Austria & Graz & 0.279 & 27 & Brazil & Brasilia & 0.239 & 51 & \multicolumn{3}{|l|}{ By region } \\
\hline Austria & Vienna & 0.313 & 18 & Brazil & Curitiba & 0.203 & 70 & Western Europe & 0.575 & 4 \\
\hline Belgium & Brussels & 0.234 & 54 & Brazil & Rio de Jane & 0.269 & 35 & Eastern Europe & 0.801 & 1 \\
\hline Denmark & Copenhagen & 0.277 & 30 & Brazil & Salvador & 0.238 & 52 & North America & 0.466 & 6 \\
\hline Finland & Helsinki & 0.268 & 36 & \begin{tabular}{|l} 
Brazil \\
\end{tabular} & Sao Paulo & 0.226 & 57 & Latin America & 0.584 & 3 \\
\hline France & Lyon & 0.259 & 41 & Chile & Santiago & 0.309 & 19 & Middle East & 0.458 & 8 \\
\hline France & Marseille & 0.248 & 47 & Colombia & Bogota & 0.328 & 13 & Africa & 0.570 & 5 \\
\hline France & Nantes & 0.249 & 45 & Mexico & Mexico City & 0.280 & 26 & Asia & 0.625 & 2 \\
\hline France & Paris & 0.214 & 65 & \multicolumn{4}{|l|}{ Middle East } & Oceania & 0.458 & 7 \\
\hline
\end{tabular}

\begin{tabular}{l|lrr|}
\hline Germany & Berlin & 0.251 & 43 \\
\hline Germany & Frankfurt & 0.263 & 39 \\
\hline Germany & Hamburg & 0.268 & 37 \\
\hline Germany & Dusseldorf & 0.322 & 16 \\
\hline Germany & Munich & 0.271 & 32 \\
\hline Germany & Ruhr & 0.260 & 40 \\
\hline Germany & Stuttgart & 0.297 & 21 \\
\hline Greece & Athens & 0.213 & 66 \\
\hline Italy & Milan & 0.238 & 53 \\
\hline Italy & Bologna & 0.231 & 55 \\
\hline Italy & Rome & 0.243 & 50 \\
\hline Netherlands & Amsterdam & 0.288 & 22 \\
\hline Norway & Oslo & 0.244 & 48 \\
\hline Spain & Barcelona & 0.224 & 59 \\
\hline Spain & Madrid & 0.257 & 42 \\
\hline Sweden & Stockholm & 0.265 & 38 \\
\hline Switzerland & Berne & 0.315 & 17 \\
\hline Switzerland & Geneva & 0.278 & 29 \\
\hline Switzerland & Zurich & 0.275 & 31 \\
\hline United Kingdom & Glasgow & 0.216 & 62 \\
\hline United Kingdom & London & 0.281 & 25 \\
\hline United Kingdom & Manchester & 0.202 & 71 \\
\hline United Kingdom & Newcastle & 0.244 & 49 \\
\hline Eastern Europe & &
\end{tabular}

\begin{tabular}{|l|l|r|r|}
\hline Israel & Jerusalem & 0.341 & 11 \\
\hline Israel & Tel Aviv & 0.175 & 85 \\
\hline Iran & Mashhad & & \\
\hline Iran & Tehran & 0.204 & 68 \\
\hline Saudi Arabia & Riyadh & 0.176 & 84 \\
\hline United Arab Emirates & Abu Dhabi & 0.363 & 10 \\
\hline United Arab Emirates & Dubai & 0.100 & 97 \\
\hline
\end{tabular}

Africa

Africa
\begin{tabular}{|l|l|r|r|}
\hline Egypt & Cairo & 0.206 & 67 \\
\hline Ivory Coast & Abidjan & 0.249 & 44 \\
\hline Morocco & Casablanca & 0.161 & 90 \\
\hline Senegal & Dakar & 0.446 & 2 \\
\hline South Africa & Cape Town & 0.162 & 89 \\
\hline South Africa & Johannesbu & 0.142 & 94 \\
\hline Tunisia & Tunis & 0.229 & 56 \\
\hline Zimbabwe & Harare & 0.382 & 6 \\
\hline
\end{tabular}

Asia

\begin{tabular}{|l|l|l|l|}
\hline China & Beijing & 0.368 & 7 \\
\hline
\end{tabular}

\begin{tabular}{l|l|l|l|}
\hline China & Being & 0.368 & 7 \\
\hline
\end{tabular}

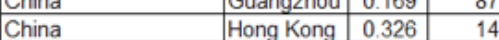

\begin{tabular}{|l|l|r|r|}
\hline China & Shanghai & 0.283 & 24 \\
\hline India & Chennai & 0.339 & 12 \\
\hline
\end{tabular}

India

\section{Oceania}

India

\begin{tabular}{l|l} 
Eastern Europe \\
\hline Czech Republic & Prague
\end{tabular}

\begin{tabular}{l|l|r|r|}
\hline Czech Republic & Prague & 0.472 & 1 \\
\hline Hungary & Budapest & 0.323 & 15 \\
\hline Poland & Cracow & 0.305 & 20 \\
\hline Russia & Moscow & 0.365 & 9 \\
\hline
\end{tabular}

India

Indonesia

\begin{tabular}{l} 
Japan \\
\hline Japan \\
\hline
\end{tabular}

Japan

Japan

North America

\begin{tabular}{l|l|l|l|}
\hline Canada & Calgary & 0.215 & 64 \\
\hline
\end{tabular}

Malaysia

Philippines

Singapore

South Korea

\begin{tabular}{l} 
South Korea \\
\hline Taiwan \\
\hline
\end{tabular}

Thailand

Vietnam

Oceania

Oceania
\begin{tabular}{|l|l|r|r|}
\hline Australia & Brisbane & 0.181 & 81 \\
\hline Australia & Melbourne & 0.182 & 80 \\
\hline Australia & Perth & 0.218 & 61 \\
\hline Australia & Sydney & 0.180 & 82 \\
\hline New Zealand & Wellington & 0.184 & 78 \\
\hline
\end{tabular}

Delhi

Mumbai

Jakarta

Osak

Sapporo 0.389

Shizuoka

Tokyo

Manila

Singapore

\begin{tabular}{ll}
\hline Singapore & 0.279 \\
\hline Seoul & 0.248 \\
\hline
\end{tabular}

\begin{tabular}{ll}
\hline Taipei & 0.269 \\
\hline
\end{tabular}

United States Atlanta

United States Chicago

United States Denver

United States Houston

United States Los Angeles

United States $\quad$ New York

United States Phoenix

United States San Diego

United States San Francisco

United States Washington

New Zealand

Wellington

Figure 1: TOTAL sustainability score of public transport in cities—normalized scores 
Latin America is rated third place because it has a second-place rank for service effectiveness and economic indicators but 6 th and 7 th place for social and environmental indicators. The Middle East is rated 5 th out of the 8 regions including a last place rating for environmental indicators, a second last for social and a 4th and 5 th place rating for economic and service effectiveness indicators.

In general, the results suggest that Western developed countries (Western Europe, North America and Oceania) have better performance on environmental and social indicators but poorer performance on service effectiveness and economic indicators. Asia and Latin America perform the other way around; better on economic and service effectiveness and worse on social and economic. Eastern Europe is one of the few with higher level performance all round.

The city based results suggest the highest rated sustainability performance of urban public transport are in Prague, Dakar and Tokyo. Prague had the top score for social indicators and second top for system effectiveness Indicator ratings amongst all cities analyzed. In terms of social indicators it has very high access (top 4 for pkms/capita), very low cost and short travel distance. In terms of system effectiveness it has the highest trips per capita of all cities (1,041 p.a.) and is in the top 4 for mode split (52.8\%) and PT fleet size. Dakar rated 2nd due to its high economic and environmental indicator ratings. Its economic performance rates from one of the highest passenger $\mathrm{km}$ ratings per GDP and is clearly influenced by a low overall GDP performance but with high usage. In environmental terms it has one of the lowest pollutant emission levels of all international cities. Tokyo by contrast has top environmental. Social indicator performance and good performance in all other indicators. Its environmental credentials result from some of the lowest energy use and emission rates of cities. In social indicator terms it has high accessibility (pkm per capita) and low average trip distance.

The worst performing cities are, in order, Dubai, Shizuoka (Japan), Denver, and Johannesburg. Dubai has one of the highest shares of its territory devoted to the use of public transit (37\%) which is an important environmental indicator. It also has poor ratings for all other Indicators (all are well below average). Shizuoka (Japan) has below average ratings for all indicators which were available. Denver is in the world lowest group for Service effectiveness and economic Indicators. Its PT trips per capita (18.25) and mode share (1.43\%) are amongst the lowest in the cities studied. Lastly Johannesburg performs poorly in all areas but particularly the social and service effectiveness areas. Its average trip distance is the highest in the world (36kms) while it also has low trip rates per capita.

\subsection{Disaggregate city/region score results}

Figure 2 shows the distribution of individual component indicator scores by city for the economic, social, environmental and effectiveness ratings. The highest rated cities by indicator are as follows:

- Environmental: Tokyo, Osaka (Japan) and Chennai (India).

- Social: Prague, Dusseldorf and Berne

- Economic: Harare and Dakar (Africa) and Ho Chi Min City (Vietnam)

- Service Effectiveness: Manila, Prague and Mumbai 

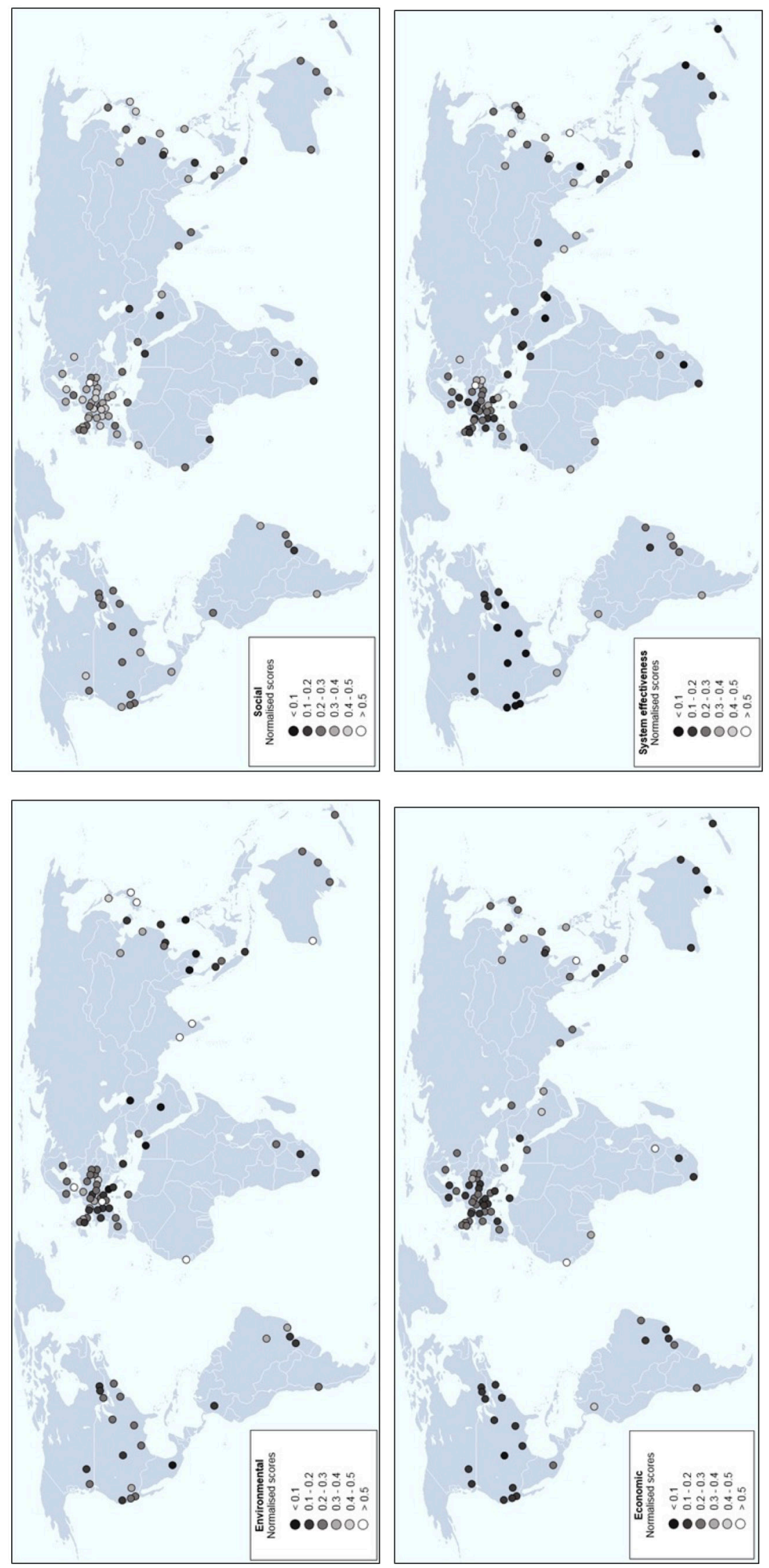

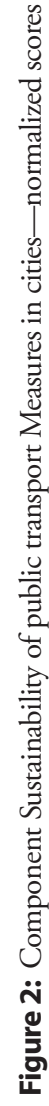


The worst performing cities in the disaggregate analysis are:

- Environmental: Manila, Bangkok and Bologna (Italy)

- Social: Ho Chi Min City, Cape Town and Riyadh (KSA)

- Economic: Melbourne (Australia), ${ }^{6}$ Denver and Paris

- Service effectiveness: Riyadh (KSA) and Phoenix, Denver and San Diego in USA.

\subsection{Correlation analysis - sustainability indicators and land-use variables}

Table 4 presents the results of the correlation analysis with land-use variables.

Table 4: Correlation of land-use indicators with urban public transport sustainability

\begin{tabular}{|c|c|c|c|c|c|c|}
\hline \multirow{2}{*}{ Land-use indicator } & \multirow{2}{*}{$\mathbf{n}$} & \multicolumn{5}{|c|}{ Correlation coefficient $(\mathbf{r})$} \\
\hline & & Environmental & Social & Economic & System effectiveness & Total \\
\hline Urban population & 97 & 0.05 & -0.11 & 0.12 & $0.33^{* * *}$ & $0.19^{*}$ \\
\hline Urban population density & 97 & 0.07 & -0.08 & $0.36^{* * *}$ & $0.54^{* * *}$ & $0.36^{* * *}$ \\
\hline Urban job density & 97 & -0.05 & -0.02 & $0.30^{* * *}$ & $0.51^{* * *}$ & $0.34^{* * *}$ \\
\hline Size of urban area & 97 & 0.04 & -0.07 & -0.13 & -0.13 & -0.12 \\
\hline Sprawl index & 41 & 0.04 & -0.25 & 0.12 & $-0.29 *$ & -0.20 \\
\hline Walking mode split & 96 & 0.05 & 0.01 & $0.20^{* *}$ & $0.26^{* * *}$ & $0.21^{* *}$ \\
\hline
\end{tabular}

This indicates that for the overall total sustainability score:

- Population and job density indicators present the highest correlation with the overall aggregate sustainability indicator with correlation coefficients of $0.36 / 0.34$ respectively at a high degree of statistical confidence. The implication is that about a third of overall sustainability performance of public transport in cities might be explained by land use. Higher density land use improves sustainability performance.

- No other land-use indicators are related to aggregate sustainability performance at a high level of statistical confidence.

- Walk mode split is correlated $(\mathrm{r}=0.21)$ with aggregate sustainability score at the $95 \%$ confidence level.

For the component sustainability indicator areas Table 4 indicates that:

- In general land-use variables are more related to system effectiveness sustainability measures and also to economic measures (but at a lower level of correlation). Land-use measures were not related to environmental or social sustainability indicators.

- A strong correlation exists between urban population/job density and system effectiveness $(\mathrm{r}=$ $0.54 / 0.51$ respectively) at a high degree of statistical confidence.

- Total population size is also linked to system effectiveness measures $(r=0.33)$ at a high degree of statistical confidence. Walking mode split is also closely correlated $(r=0.21)$ to system effectiveness sustainability measures again at a high degree of statistical confidence.

- Population and job density is also correlated with economic sustainability metrics $(r=0.36 / 0.30)$ at a high degree of statistical confidence. Walk mode share is also related to economic metrics but with low correlation $(r=0.20)$ and statistical confidence $(95 \%)$.

\footnotetext{
${ }^{6}$ Melbourne has the lowest rank for world cities on economic sustainability measures. This is due to poor ratings on all economic indicators including cost recovery (34\%) and long average PT trip times (57mins)
} 


\subsection{Regression modelling results}

Results from the regression modelling are presented in Table 5. Only two land-use indicators, urban population density and urban job density, were found to be statistically significant predictors of public transport sustainability. Both these variables had a Variance Inflation Factor (VIF) value of less than 5, indicating no evidence of multicollinearity. The inclusion of other (non-significant) land-use indicators in the regression models only reduced the significance of the results so these variables were excluded from the final models shown in Table 5. Regression models for environmental or social sustainability are also not shown in Table 5 as these were not statistically significant. This is the consistent with the results of the correlation analysis (Section 4.3) which showed little association between land-use indicators and environmental or social sustainability.

Table 5: Regression modelling results for public transport sustainability

\begin{tabular}{lcccccc}
\hline \multirow{2}{*}{ Variable } & \multicolumn{2}{c}{ Economic } & \multicolumn{2}{c}{ System effectiveness } & \multicolumn{2}{c}{ Total } \\
\cline { 2 - 7 } & Coefficient & t-value & Coefficient & t-value & Coefficient & t-value \\
\hline Constant & $0.175^{* * *}$ & 9.792 & $0.122^{* * *}$ & 7.169 & $0.211^{* * *}$ & 18.457 \\
Urban population density & $0.001^{*}$ & 2.269 & $0.001^{* *}$ & 3.558 & $0.000^{*}$ & 2.120 \\
Urban job density & 0.001 & 1.179 & $0.001^{* *}$ & 2.798 & $0.001^{* *}$ & 1.674 \\
Number of observations & 90 & & 95 & & 95 & 0.160 \\
$\mathrm{R}^{2}$ & 0.141 & & 0.348 & & $\mathrm{p}<0.001$ \\
Model significance & $\mathrm{p}<0.01$ & & $\mathrm{p}<0.001$ & & & \\
\hline
\end{tabular}

Note: All explanatory variables had a Variance Inflation Factor (VIF) value of less than 5, indicating no issues of multicollinearity. Regression models were not statistically significant for environmental or social sustainability. ${ }^{*} \mathrm{p}<0.05,{ }^{*} \mathrm{p}<0.01$, ${ }^{* * *} \mathrm{p}<0.001$.

\subsection{Sustainability indicators and land use by city}

Of the land-use variables explored, population and job density had the strongest correlations with Aggregate Sustainability Score. Figure 3 shows the relationship between individual city score and urban population and job density. The best fit trend line for the aggregate scores was curvo-linear (all forms were tested) but with a relatively low overall fit size $\left(R^{2}=0.15\right.$ for population density and 0.18 for job density). There is a wide degree of dispersion of cities around the regression line. For population density, most cities lie in the 10 to 80 persons per hectare level of density where links to overall sustainability performance scores are just not clear. Cities like Prague have high sustainability score but modest population density. For job density again most cities lie in the lower density range but have a wide range of sustainability scores; Prague again stands out as an outlier.

Figure 4 shows the distribution of system effectiveness scores against population and job density. A much clearer relationship is demonstrated with a strong fit $\left(\mathrm{R}^{2}=0.36\right.$ for population density and a very high 0.43 for job density). Prague, Budapest and Manila all have consistently higher service effectiveness performance above the trend for both their population and employment density. Conversely Casablanca, Ho Chi Min City and Delhi all appear to have lower service effectiveness scores than the trend for both their population and employment densities.

\section{$5 \quad$ Discussion and conclusions}

This paper explores links between land use and public transport sustainability for cities throughout the world. Population and job density indicators present the highest correlation with the overall ag- 
gregate sustainability indicator with correlation coefficients of $0.36 / 0.34$ respectively at a high degree of statistical confidence. The implication is that about a third of overall sustainability performance of public transport in cities might be explained by land use. Higher density land use improves sustainability performance. Analysis has shown that a wider range of land-use indicators are more strongly correlated with the service effectiveness categories of sustainability indicators and, to a lesser extent the economic sustainability indicators. A strong correlation exists between urban population and job density (0.54/0.51 respectively) at a high degree of statistical confidence. Total population size is also linked to system effectiveness measures (0.33) as well as Walk mode split (0.21).

To better understand the nature of these links it is useful to understand the component variables used in the system effectiveness measures. These include vehicle occupancy rates (D1), Annual PT trips per capita (D2), PT mode split (D3) and PT fleet size (D4). All are widely acknowledges as factors related to urban density (Kenworthy \& Laube, 1999; Ewing \& Cervero, 2010). Job density seems to be particularly strongly related to Service Effectiveness (Figure 4, bottom) which may be suggestive of a role for strong core centers of employment in central business districts encouraging high ridership effectiveness.

Overall the results suggest that land use, notably density acts to influence the sustainability of an urban public transport but that this influence is not dominant; rather it is one of many factors of which design, funding, good management and policy are other likely influencers. 


\section{POPULATION DENSITY}

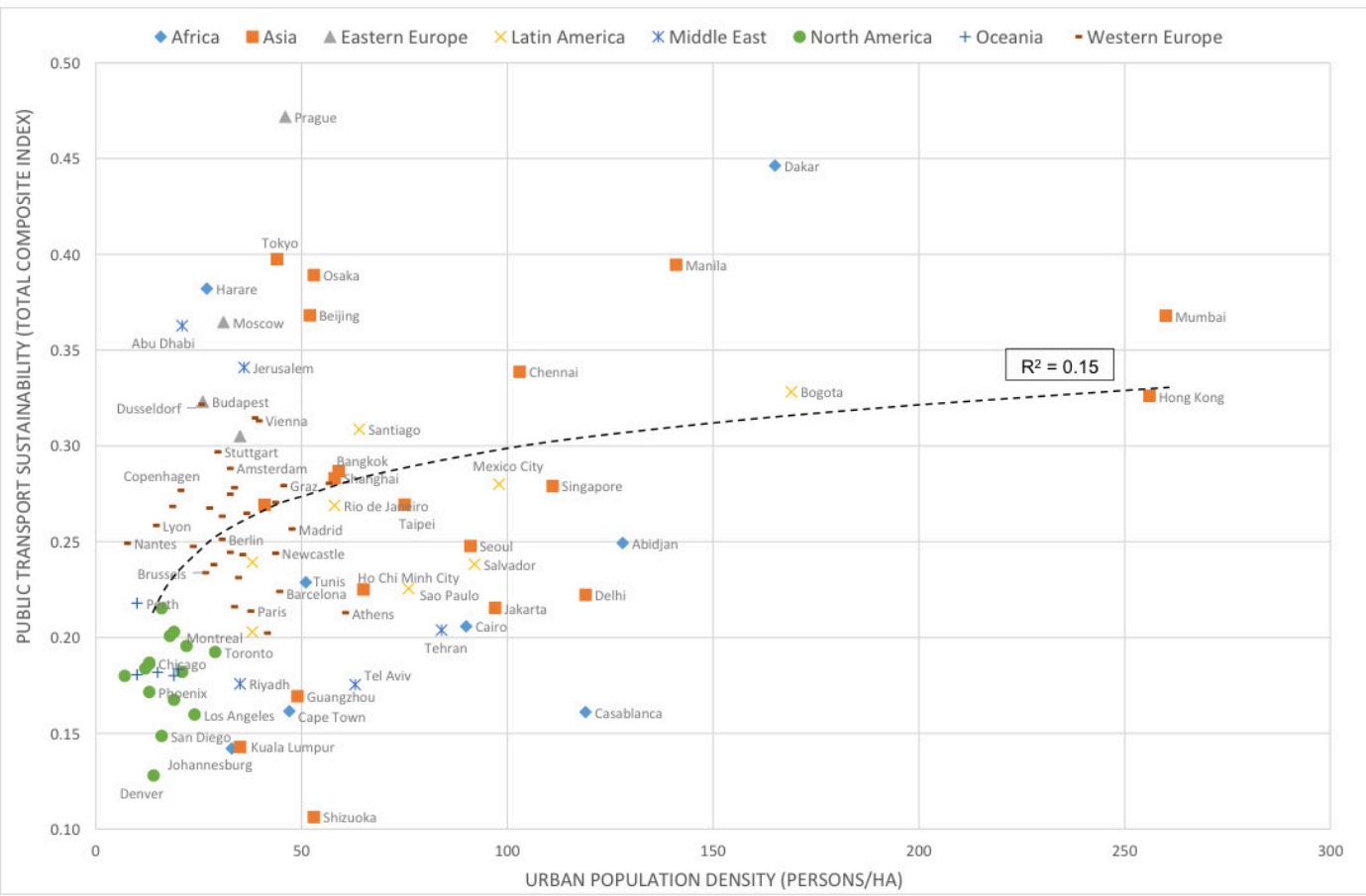

\section{JOB DENSITY}

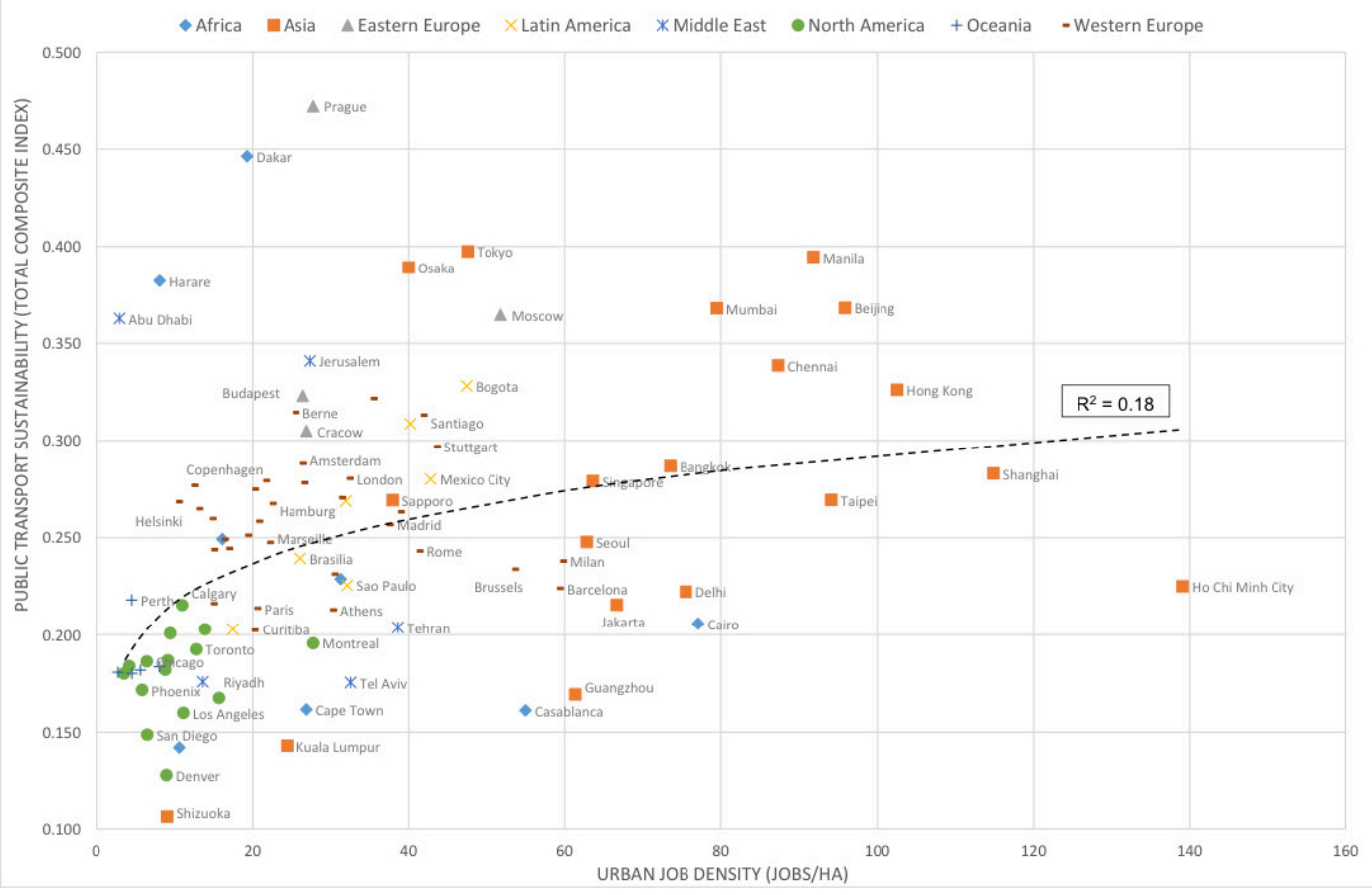

Figure 3: Aggregate sustainability of public transport by population and job density 


\section{POPULATION DENSITY}

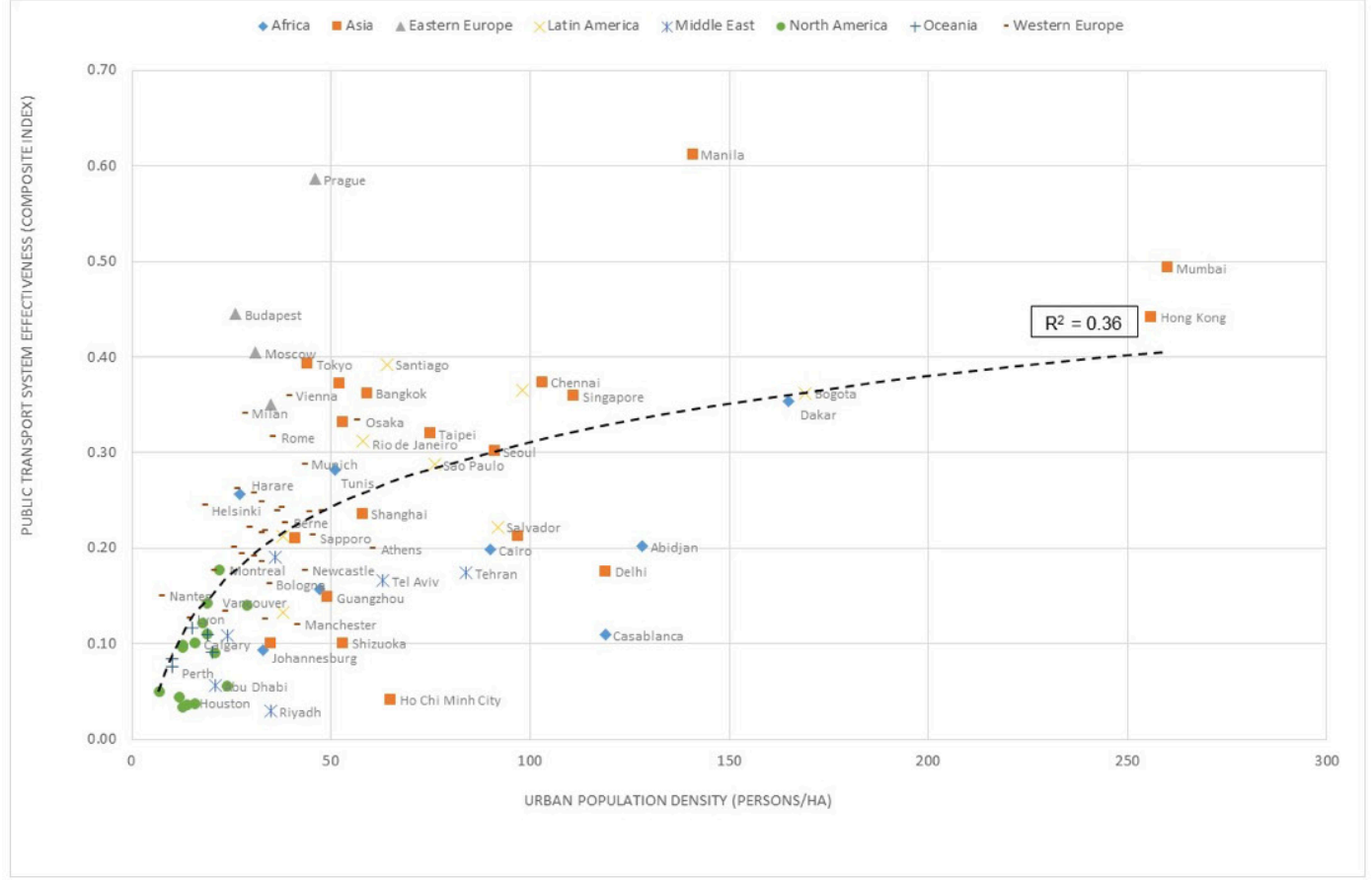

\section{JOB DENSITY}

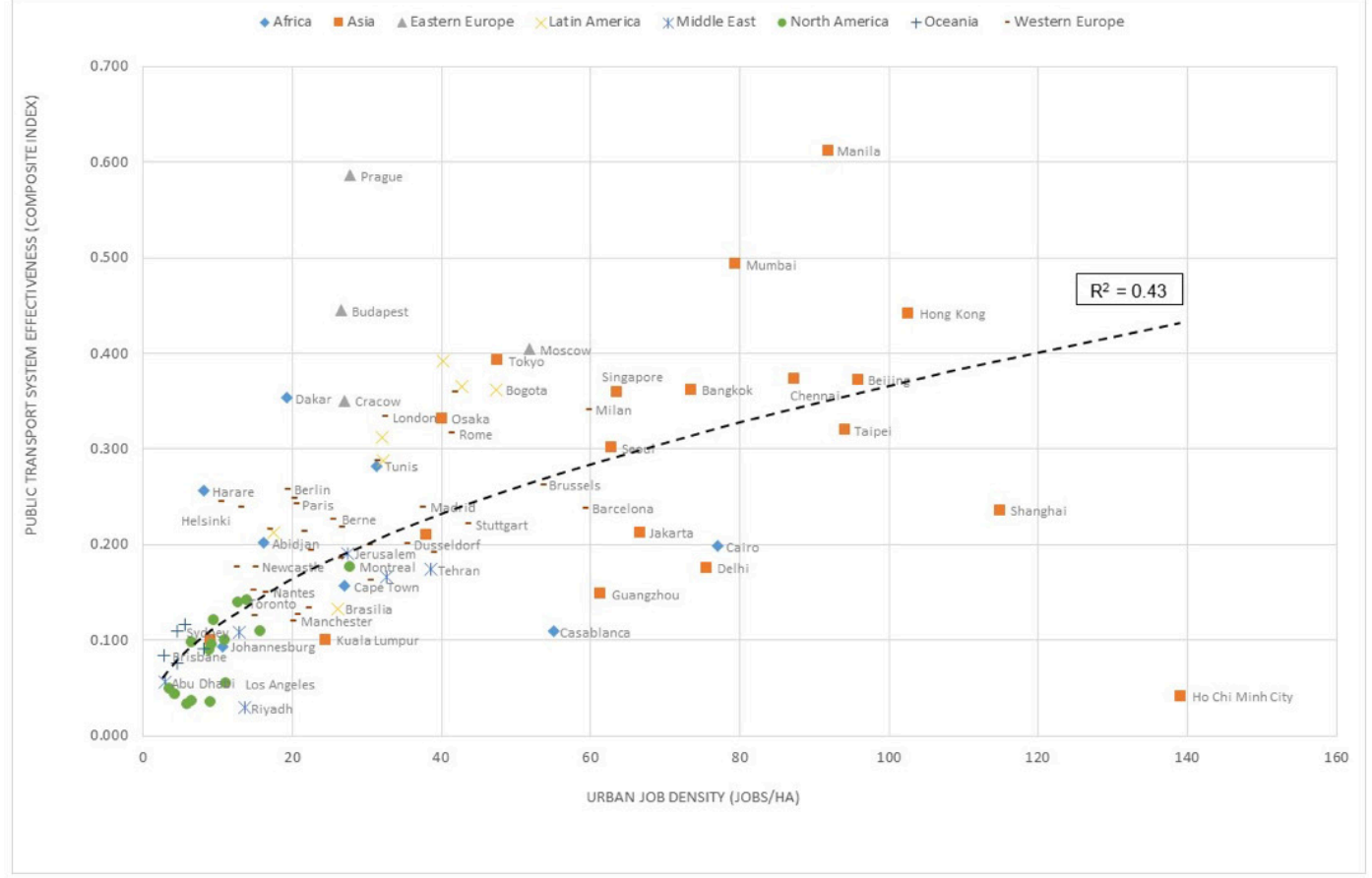

Figure 4: Aggregate system effectiveness sustainability of public transport by population and job density 
The results imply that public transport systems in Western contexts should address shortfalls in their service effectiveness and economic sustainability performance to better improve their overall sustainability. The results suggest that increasing land use density (both population and jobs) may be an effective means of achieving this end. This might suggest that policies aimed at Transit Oriented Development or Urban Consolidation are appropriate for Western cities. However, results presented are aggregate total city wide results; this implies a need to increase density throughout a city as well to concern policy around localized density needs at transit rich locations. In Asian and South American contexts, service effectiveness and economic is good and might be linked to better overall city wide land-use densities. In these contexts, improved sustainability requires a focus on environmental and social sustainability. However, performance in these regions varies so some cities might well adopt land-use densification strategies where there is room to improve.

Regarding future research, there is much scope to improve on the sustainability metrics developed and to better weight the importance of component indicators relative to their influence on overall sustainability. A more disaggregate consideration of the range of policies being adopted in the cities studies might also identify patterns in relation to sustainability performance.

A major concern with the analysis methodology is the limitations of the indicators available. For example, land-use indicators are highly related suggesting a degree of collinearity which might affect the quality of the findings made. There are also links between the performance data and prevailing economic conditions and policy contexts in cities/countries studied and not all such factors are captured with the use of GDP or relative $\$$ US values. This problem plagues all research concerning global comparisons so this research is no exception but it is wise for the reader to be aware of such limitations. Any policy implications which readers might draw should be aware of these limitations.

There are also concerns regarding the specific form of individual indicators; for example, mass of pollutants are measured per hectare (rather than per passenger $\mathrm{km}$ ) and this could act to bias results in favor low density cities. There is certainly room to better measure the facets of sustainability in a more reliable way but data limitations are the cause of most of these concerns. Again, readers should be aware of these limitations in drawing conclusions regarding this research.

The selection of world regions adopted in this analysis are also open to question; the authors selected the regions adopted by UITP in the source data used for the research however some of these regions are rather diverse in nature (e.g., Asia) and there is much variation in performance of cities within these regions. Nevertheless, there is a need to summarize the results of the 96 cities studied to some form of aggregation of cities.

Another suggestion for future research in this analysis is to explore the public transport sustainability research presented in this paper with those from other research covering the whole transport system. While we argue public transport itself should be sustainable clearly the sustainability of the wider system, including land use, is an important area to explore.

Overall, it is clear that urban public transport must look to improve its own sustainability performance if we are to achieve the challenging targets set by the United Nations in the Global Sustainability Goals. Land use and urban form play an important though not a dominant part in public transports' sustainability performance. However, there is much room to improve performance by adopting progressive land-use strategies as well as by addressing environmental and social sustainability challenges into the 21 st century. 


\section{References}

Brundtland Commission. (1987). Report of the World Commission on Environment and Development: Our common future. New York: United Nations.

Castillo, H., \& Pitfield, D. (2010). ELASTIC-A methodological framework for identifying and selecting sustainable transport indicators. Transportation Research Part D, 15, 179-188.

Cervero, R. (2013). Linking urban transport and land use in developing countries. Journal of Transport and Land Use, 6(1), 7-24.

De Gruyter, C., Currie, G., \& Rose, G. (2017). Sustainability measures of public transport in cities: A world review and focus on the Asia/Middle East region. Sustainability, 9(1), 43.

Demographia. (2016). Demographia world urban areas, 12th annual edition. Belleview, IL: Demographia.

Dobranskyte-Niskota, A., Perujo, A., \& Pregl, A. (2007). Indicators to assess sustainability of transport activities, Part 1: Review of the existing transport sustainability indicators initiatives and development of an indicator set to assess transport sustainability performance. Ispra, Italy: European Commission, DG Joint Research Center Institute for Environment and Sustainability.

Ewing, R., \& Cervero, R. (2010). Travel and the built environment: A meta-analysis. Journal of the American Planning Association, 76(3), 265-294.

Geerlings, H., \& Stead, D. (2003). The integration of land use planning, transport and environment in European policy and research. Transport Policy, 10(3), 187-196.

Griggs, D., Stafford-Smith, M., Gaffney, O., Rockström, J., Öhman, M., Shyamsundar, P., Steffen, W., Glaser, G., Kanie, N., \& Noble, I. (2013). Sustainable development goals for people and planet. Nature, 495(7441), 305-307.

Haghshenas, H., \& Vaziri, M. (2012). Urban sustainable transportation indicators for global comparison. Ecological Indicators, 15, 115-121.

Jeon, C. M., Amekudzi, A., \& Guensler, R. L. (2010). Evaluating plan alternatives for transportation system sustainability: Atlanta Metropolitan Region. International Journal of Sustainable Transportation, 4(4), 227-247.

Kenworthy, J. R., \& Laube, F. B. (1999). Patterns of automobile dependence in cities: An international overview of key physical and economic dimensions with some implications for urban policy. Transportation Research Part A, 33, 691-723.

Litman, T. (2009). Sustainable transportation indicators: A recommended research program for developing sustainable transportation indicators and data. Paper presented at the 88th Transportation Research Board (TRB) Annual Meeting, Washington, DC.

Litman, T. (2016). Land use impacts on transport: How land-use factors affect travel behavior. Victoria, BC: Victoria Transport Policy Institute (VTPI).

Miller, P. (2014). Sustainability and public transportation: Theory and analysis (doctoral dissertation). Calgary, Manitoba: University of Calgary.

Miller, P., de Barros, A. G., Kattan, L., \& Wirasinghe, S. C. (2016). Analyzing the sustainability performance of public transit. Transportation Research Part D, 44, 177-198.

Newman, P., \& Kenworthy, J. R. (2006). Urban design to reduce automobile dependence. Opolis: An International Journal of Suburban and Metropolitan Studies, 2(1), 35-52.

OECD. (2016). OECD Metropolitan eXplorer. Retrieved from http://measuringurban.oecd.org/

Schwarz, N. (2010). Urban form revisited—selecting indicators for characterizing European cities. Landscape and Urban Planning, 96, 29-47.

The Brookings Institution. (2016). Global metro monitor 2014: An uncertain recovery. Washington, DC: The Brookings Institution. 
UITP. (2001). Millenium cities database for sustainable mobility. Brussels: International Association of Public Transport.

UITP. (2015). Mobility in cities database 2015. Brussels: International Association of Public Transport. United Nations. (2015). Transforming our world: The 2030 agenda for sustainable development. New York: United Nations.

Vuchic, V. (1999). Transportation for livable cities. New Brunswick, NJ: Rutgers, State University of New Jersey, Center for Urban Policy Research. 